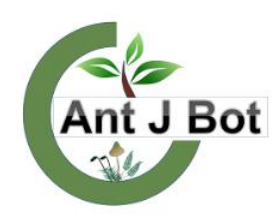

Received : 07.08.2020

Accepted : 26.10 .2020

Online $\quad: 27.10 .2020$

\section{Biofilm formation mechanism in fungi}

\author{
Dilek UZUNDA $\breve{G}^{\mathbf{1}^{*} \odot \text {, Ebru Şebnem YILMAZ }}{ }^{\mathbf{D}}$, Hayri BABA ${ }^{\mathbf{3}}$ \\ ${ }^{1,2,3}$ Mustafa Kemal University, Science \& Arts Faculty, Department of Biology, Hatay, Turkey \\ *dilekuzundag@gmail.com. ${ }^{2}$ ebrusebnem@hotmail.com,3hayribaba@mku.edu.tr
}

\begin{abstract}
The biofilm problem is a problem that is commonly encountered in many areas of industry and causes serious economic losses. It is stated in the literature that biofilms can be removed from surfaces by appropriate cleaning methods. However, biofilm formation gains continuity over time. Biofilm studies are generally on bacteria. Microorganisms that cause infection in humans include bacteria, viruses, and fungi. In biofilm-borne infections, there may be only one or a combination of various microorganisms. Nowadays, new searches are in progress due to the ineffectiveness of synthetic drugs against fungal diseases, their side effects, and the increase of the number of pathogenic microorganisms that are rapidly resistant to existing antifungals. Therefore, the prevention of biofilm formation is now one of the most important studies worldwide.
\end{abstract}

Key words: Antifungal, biofilm, fungal resistance

Özet: Biyofilm sorunu endüstrinin birçok alanında yaygın olarak rastlanılan bir sorundur ve ciddi anlamda ekonomik kayıplara neden olmaktadır. Literatürde uygun temizleme yöntemleri ile biyofilmlerin yüzeylerden uzaklaştırılabileceği belirtilmektedir. Ancak zamanla biyofilm oluşumu süreklilik kazanır. Biyofilm çalışmalarının geneli bakteriler üzerinedir. İnsanlarda enfeksiyona neden olan mikroorganizmalar arasında bakteriler, virüsler ve funguslar bulunmaktadır. Biyofilm kaynaklı enfeksiyonlarda etken tek olabileceği gibi bazı mikroorganizmaların karışımıda olabilir. Günümüzde artan fungal hastalıklara karşı sentetik yapılı ilaçların yetersiz kalması, yan etkileri ve mevcut antifungallere hızla direnç kazanan patojen mikroorganizmaların sayısının artması ile yeni arayışlar devam etmektedir. Bütün bunlara bağlı olarak da biyofilm oluşumunun önlenmesi artık tüm dünyada önem arz eden çalışmaların başında gelmektedir.

Anahtar Kelimeler: Antifungal, biyofilm, fungal direnç

Citation: Uzundağ D, Yılmaz EŞ, Baba H (2020). Biofilm formation mechanism in fungi. Anatolian Journal of Botany 4(2): 116-120.

\section{Introduction}

Biofilm is a matrix created by microorganisms, which consists of extracellular polymeric material, allows them to adhere to any surface, interface, or to each other, and in which microorganisms showing and creating different phenotypes depending on growth rates and gene transcription are embedded (Szafrański et al., 2017).

There are a limited number of studies on fungal biofilms in the literature. Fungal biofilm-forming species are limited to a few species that are differentiated as endogenous and exogenous in medical use and easy to isolate rather than in industrial use. The main ones are; Candida Berkhout spp. (C. albicans (C.P.Robin) Berkhout), Cryptococcus neoformans (San Felice) Vuill., Blastoschizomyces Salkin, M.A. Gordon, Sams. \& Rieder spp., Malassezia Baill. spp., Trichosporon Behrend spp., Pneumocystis P.Delanoë \& Delanoë spp., Saccharomyces Meyen spp., Aspergillus P.Micheli ex Haller spp. (A. fumigatus Fresen.) and Coccidioides immitis C.W.Stiles (Andersen et al., 2014). The fungal cells in the biofilm matrix differ from those that develop planktonically. Biofilms protect cells against adverse environmental conditions such as UV, metal toxicity, $\mathrm{pH}$, osmotic changes, dehydration, antimicrobial agents, and disinfectants (Dimakopoulou-Papazoglou et al., 2016).

This research aims to support future studies for the ease of treatment and the elimination of high costs by examining the fungal biofilm mechanism in the prevention of biofilms caused by fungi in the industrial and medical sectors.

\subsection{Fungal biofilms}

1.1.1. Biofilms in industrial, environmental, and agricultural fields

It is stated that biofilms cause economic losses due to their negative effects in industrial, environmental, and agricultural areas (Van and Michiels, 2010). The damage on surfaces (on instruments), product contaminations, energy losses and disease-causing infections due to biofilms cause losses worth millions of dollars in the United States. Biofilms are responsible for product and capital equipment damage (pipe clogging, rusting, and water pollution) every year in the industry (Güvense and Ekmekcioğlu, 2016).

\subsubsection{Biofilms in the food industry}

Biofilms, one of the most important sources of foodborne infections, cause serious problems in the food industry. Among the sectors affected by fungal biofilms is a wide range of products such as seafood, dairy products, poultry, and meat enterprises (Akan and Kınık, 2014). Due to biofilm formation, many problems such as film accumulation on the food surface, microbial colonization in milk storage tanks, contamination in heat exchangers, and sports adhesion on the surface of the packaging material arise (Brooks and Flint, 2008). In the milk industry, the biofilm matrix predominantly includes milk residues, proteins, and minerals like calcium phosphate, etc, and biofilm is the first important reason that comes to mind when any contamination occurs in dairy products (Simões et al., 2010). 


\subsubsection{Biofilms in medicine}

In biofilm-borne infections, the factor can be a single bacterium or a mixture of bacteria and fungal species. Infections caused by fungi negatively affect human health. Many medically important fungi produce biofilms, including Candida, Aspergillus, Cryptococcus Vuill., Trichosporon, Coccidioides C.W.Stiles, and Pneumocystis. The use of broad-spectrum antibiotics, neutropenia, parenteral nutrition, permanent catheters, immunosuppression, and disruption of mucosal barriers secondary to surgery, chemotherapy, and radiotherapy are important factors for these infections (Allison et al., 2000).

The mechanisms used by biofilm-related organisms that cause infections in humans have not yet been fully understood. Among the proposed mechanisms is the emergence of infection in the blood or urinary system due to cells or cell groups separated from the biofilm on implants, endotoxin production, continuation of existence against the host immune system by gaining antimicrobial agent resistance through genetic substance transfer through showing structural resistance (DimakopoulouPapazoglou et al., 2016). In models of Candida biofilms, yeast cells adhere to a live or inert surface and initially maintain a yeast-like morphological form. Candida albicans biofilms are comprised primarily of yeast-form and hyphal cells, both of which are required for biofilm formation. Formation is a sequential process involving adherence to a substrate (either abiotic or mucosal surface), proliferation of yeast cells over the surface, and induction of hyphal formation. As the fungal biofilm matures, yeast-like growth is repressed and hyphal growth expands. As the hyphae spread across the surface, an extracellular matrix is secreted and surrounds the fungal biofilm, thereby gluing the hyphae together. The expanded hyphal growth and surrounding matrix can be considered characteristic features of fungal biofilms. Aspergillus biofilms can form both on abiotic and biotic surfaces. The initial colonizing cells that adhere to the substrate are conidia. Mycelia (the hyphal form) develop as the biofilm matures. Although Cr. neoformans forms hyphae in the course of mating, no hyphae have been observed in $C r$. neoformans biofilms to date. Similarly, Pneumocystis species do not produce hyphal structures as part of their biofilms. Thus, hyphal formation is not a uniform feature of fungal biofilms (Foreman et al., 2009; Fanning and Mitchell, 2012).

Biofilms formed by microorganisms are responsible for approximately $65 \%$ of nosocomial infections. Diseases such as inflammation of the internal wall of the heart, periodontitis, cystic fibrosis are some of the diseases caused by these microorganisms. The biofilm matrix reduces the penetration of antimicrobial agents (Szafrański et al., 2017). Besides, $2 \%$ of the plastic surgery operations performed in the USA require replacement of the prosthesis due to biofilm infections. In addition, these microbial communities are naturally more resistant to antibiotics and other forms of antimicrobial therapy. This causes recurrent infections in clinical terms. Orthopedic prostheses, catheters, contact lenses, intrauterine devices, ophthalmic implants, vascular stents, and mechanical heart valves can be listed among the examples of medical materials that cause biofilm infections (Costerton et al., 1999). Fungal biofilms are an important health problem that causes about $80 \%$ of hospital infections however, infections caused by them are complicated.

Fungi are increasingly recognized as able to adopt a biofilm phenotype both on live and abiotic surfaces. Much of the work in fungal biofilm research has focused on Candida species involved in indwelling medical device infection. Although vast ranges of fungal species are isolated from CRS patients, Candida species are rarely seen. Aspergillus fumigatus, however, is a frequent sinonasal pathogen and is known to form biofilms on bronchial epithelium (Fanning and Mitchell, 2012).

\subsection{Fungal biofilm formation}

It has been determined that the structure of the biofilm is specific to the species in pure cultures and to the substrate in multiple cultures. It is known that the structure of heterogeneous biofilms is mostly irregular. Microorganisms in biofilms have been proven to be resistant to environmental conditions such as $\mathrm{pH}$, temperature, pollutants, hydraulic shock, antibiotics and toxic substances (Dimakopoulou-Papazoglou et al., 2016).

Biofilm formation has been identified in prokaryotic microorganisms such as Gram-negative Pseudomonas aeruginosa Schröter and eukaryotic fungi such as $S$. cerevisiae (Desm.) Meyen, C. albicans, and C. glabrata (H.W. Anderson) S.A. Mey. \& Yarrow. There are serious differences between their fungal biofilm-forming forms and free-living forms, and different opinions are announced about the situations that require bacteria to form biofilms. When we compile these studies, we can list the causes of biofilm formation as follows. These are defense, adhesion, and colonization, the formation of a viable environmental and community building. Facilitating the storage of foods and removal of waste are among other advantages of biofilm formation. Because the yeasts are found in clusters and in the extracellular matrix, they become difficult to phagocyte and the humoral immune system components are prevented from reaching the yeasts. The distinctive feature of $C$. albicans biofilms is that different morphological forms coexist. C. albicans biofilm formation occurs in 3 stages: Early phase (0-11 hours), intermediate phase (12-30 hours), and mature phase (38-72 hours) (Fleming and Rumbaugh, 2017; Kumamoto, 2005).

\subsection{The biofilm formation mechanism}

It is very common to find microbial biofilms in the environment and even on fomit surfaces with other commensal species. Bacteria and fungi can both form biofilms on surfaces, but some factors that arise during their formation are different (D'Acunto et al., 2015). A better understanding of the structure and mechanisms of biofilms will reveal potential treatment goals. Biofilm formation can be defined as a 4-step process:

Attachment: It is the first phase in which planktonicstructure microorganism is reversibly attached to the surface. The bacteria attach to the surface in a short time as a result of the flagella movement and the electrostatic and physical interactions (Brownian motion) it has with the surface it is attached to. In yeast, attachment is directly related to the surface. Attachment molecules that are different from bacteria are divided into two groups as nonspecific and specific. Their molecules are the surface 
hydrophobic molecules and the receptor-ligand level including Als 1, Als 3, Ace 2, Bcr 1, Hwp 1, Sun 41, Eap 1, Mnt 1, Mnt 2, Och 1, Pmr 1, respectively. The hydrophobicity of the surface also positively affects biofilm formation. Yeast cells line up in the basal layer and hyphae elements in the ESM (exopolysaccharide matrix) line up on this layer in a biphasic structure on the hydrophobic surfaces of silicone elastomer or PVC discs. However, on irregular or rough 'polymethylmethacrylate' surfaces, it has been observed that mature biofilm consists only of yeast cells and ESM (Chandra et al., 2001).

Irreversible Attachment: The irreversible attachment in mushrooms is mostly explained by studies in medicine. The first thing to do after the implantation of medical devices is the formation of a "preparatory film" by various macromolecules in different body fluids surrounding the medical device such as saliva, mucus, serum, or blood through accumulation on the surface. Microorganisms usually adhere to this film layer, not to the surface of the bare device. The first adhesion is in a reversible loose attachment style. This can turn into a tight adhesion with exopolymer production (Pascual, 2002).

Colonization and Microcolony Formation: Bacteria cells attached to the surface divide and multiply to form microcolonies. Quorum sensing (QS) is a mechanism of microbial communication dependent on cell density that can regulate several behaviors in bacteria such as secretion of virulence factors, biofilm formation, competence, and bioluminescence (Albuquerque and Casadevall, 2012). The bacterial population grows gradually with the newly formed microcolonies. The Quorum Sensing (QS) signal system is activated, which allows the bacteria to detect the population density around it. This stage is also the stage in which the biofilm phenotype begins to emerge, which may result in the microorganism gaining a resistant structure (D'Acunto et al., 2015). The existence of fungal QS systems was revealed ten years ago after the discovery that farnesol controls fi lamentation in the pathogenic polymorphic fungus $C$. albicans. In the past decade, farnesol has been shown to play multiple roles in $C$. albicans physiology as a signaling molecule and inducing detrimental effects on host cells and other microbes. In $S$. cerevisiae, two other aromatic alcohols, phenylethanol and tryptophol were found to be QSMs regulating morphogenesis during nitrogen starvation conditions (Albuquerque and Casadevall, 2012).

In fungi, exopolymers form the layer called glycocalyx (slime) by wrapping the film layer formed by macromolecules. Microorganisms multiply in this slime layer, resulting in a thick film layer. It is an important condition for nosocomial fungal infections that Candida species both play a role as a continuous focus of infection and get rid of the body's defense mechanisms and the effect of antifungal therapy as a result of adherence to medical devices through slime factor (Pittet et al., 1997).

Rupture: After biofilm formation and maturation, flagella or hyphae are synthesized as a result of genetic arrangements in bacteria or fungus cells in the biofilm. In this way, the activated microorganism cells are ruptured from the top layer of the biofilm. The ruptured planktonic cells migrate to new foci. This can lead to the spread of the biofilm and sometimes the transition of local infections to the systemic state (Kumamoto, 2011).

\subsubsection{Fungal quorum sensing}

The QS mechanism in eukaryotic microorganisms was not known until the discovery of the chemical called farnesol. The QS studies in fungi are much newer than bacteria. The fact that the cell morphology of $C$. albicans, a human pathogen, was controlled by "farnesol" was identified in 2001 (Hornby et al., 2004). The molecule called farnesol has been shown to prevent germ tube formation in the presence of three different triggers (L-proline, Nacetylglucosamine, swine, and bovine serums). It has been determined that this extracellular molecule is highly thermostable, produced in amounts proportional to the number of yeast cells in the range of $23-43{ }^{\circ} \mathrm{C}$, is effective on different $C$. albicans origins, and is not affected by the composition and structure of the medium. In a study in which more than forty farnesol analogs were tested, it was shown that the QS activity was highly related to the structure of the molecule, and this finding was due to a specific communication with a farnesol receptor (Shchepin et al., 2003). The same researchers demonstrated that the QS molecules were taken into the cell as a result of the examinations with labeled probes displaying QS activity (Shchepin et al., 2005).

The biofilm structure of $C$. albicans consists of basal yeast layer, a dense hyphae structure, and an extracellular matrix. Considering the concentration of farnesol, it is thought that farnesol can prevent biofilm formation. When the farnesol concentration reaches $300 \mu \mathrm{M} / \mathrm{l}$, biofilm formation is completely prevented (Shchepin et al., 2005). Since the discovery of farnesol, different QS molecules have been identified in different fungal species. Examples of other QS molecules are peptide-1 in Cr. neoformans, oxilipines found in A. nidulans, and tyrosol inducing filamentation in $C$. albicans. In $S$. cerevisiae, phenylethanol and triptofol are aromatic alcohols that stimulate pseudo-hyphal growth at low concentrations. These compounds are also produced by $C$. albicans (Shchepin et al., 2003).

Farnesol does not affect germ tube formation when added to A. nidulans (Eidam) G.Winter cultures; however, it triggers apoptosis in these species. Farnesol-induced apoptosis is associated with mitochondrial function. When $A$. nidulans and $C$. albicans were cultured together on the same medium, A. nidulans growth was prevented (Ramage et al., 2011). As a result, it suggests that farnesol may reduce competition with other microorganisms.

Unlike A. nidulans, farnesol does not affect the growth of A. niger Tiegh., but it causes significant changes in its morphology. At farnesol concentrations higher than 10 $\mathrm{mM}$, the conidiation is completely suppressed and a 10 fold reduction takes place in the intracellular level of cAMP (Semighini et al., 2006).

It is imperative that $C$. albicans, which is in yeast form in the gastrointestinal lumen, form a germ tube to show pathogenicity through invasion. Farnesol's ability to prevent this transformation suggests that it can be used as a new class antifungal, especially in immunosuppressed individuals. However, contrary to this in vitro effect, it is also stated that accumulation of lipophilic farnesol under in vivo conditions changes the intestinal membrane permeability and decreases protein kinase $\mathrm{C}$ activity by reducing the production of diacylglycerol, and paves the 
way for the entry of yeast cells, which have accumulated in a small area in large numbers, to the systemic circulation, leading to apoptosis (Hornby et al., 2004).

Candida albicans is also protected from oxidative stresses such as hydrogen peroxide and superoxide anion produced by some bacteria such as Enterococcus faecalis and phagocytes of the host, where it is cultured together. When $C$. albicans culture supernatants in the stagnation phase were added to $C$. albicans cultures in the logarithmic reproduction period, it was shown that they continued living under oxidative stress, under which they normally died, and this resistance occurred due to antioxidant molecules resulting from increased in CAT1, SOD1, SOD2 and SOD4 gene expression. In the same study, it was found that alphatocopherol, another molecule of QS, did not produce such a protective effect and the effect was due to farnesol (Westwater et al., 2005).

Farnesol was tested on the crepe, crater, concentric, and flat colony variants of $C$. parapsilosis, and it was observed that those except the flat type colony variant prevent biofilm formation. Besides, farnesol has been shown to reduce the reproduction and development and trigger apoptosis of $A$. nidulans, which does not produce a measurable amount of QS molecules, although it does not affect its morphogenesis (Laffey and Butler, 2005). From this point of view, it can be said that $C$. albicans uses QS molecules to gain an advantage against other microorganisms that it coexists with. A similar inhibitory effect was observed on A. fumigatus and Fusarium graminearum Schwabe (Semighini et al., 2006). It was shown that another dimorphic fungus, Ceratocystis ulmi (Buisman) C.Moreau, also had a QS molecule with similar effects, which was not effective on $C$. albicans and that this species was not affected by farnesol (Hornby et al., 2004).

Tyrosol is the second molecule of QS discovered after farnesol. Tyrosol also regulates morphogenesis depending on concentration density like farnesol (Semighini et al., 2006). Studies on $C$. albicans have shown that germ tube formation accelerates in cultures less diluted in terms of tyrosol. Based on this result, C. albicans morphogenesis is thought to be controlled depending on environmental conditions. Tyrosol induces cell growth and germ tube formation at low cell density. It accelerates the conversion from yeast form to filamentous form. In the presence and absence of tyrosol, the formation of germ tubes in $C$. albicans cells was examined, and in the presence of tyrosol, $55 \%$ of the cells at 1 hour and $80 \%$ at 2 hours were observed to form germ tubes (Chen et al., 2004).

\section{Discussion and conclusion}

The biofilm formed in the medical tools and materials used can be formed by bacteria and yeast. The presence of fungal biofilms rather than bacterial biofilms is increasingly investigated in clinical studies. The source for these microorganisms can be the patient's own flora, the hands of healthcare professionals, tap water, or environmental surfaces (Douglas, 2002).
Traditional treatments used in medicine today are not considered clinically sufficient due to the presence of bacteria that are resistant to treatment and the emergence of new resistant/highly resistant strains (biofilm-forming bacteria, yeasts, and mycobacteria). While determining future diagnosis-treatment-follow-up methods, the processes and conditions before the biofilm is formed should be taken into consideration with a proactive approach. As more detailed and specific information about the morphology and physiology of biofilms formed by fungi, which is a factor of chronic infections, is obtained; the results obtained from antifungal developments will show a noticeable improvement.

As an alternative to existing antibimicrobials in the treatment of microbial diseases, the discovery of inhibitory agents against the QS mechanism in microorganisms is very important. This will once again emphasize the importance of elucidating the QS mechanism. Since antifungal resistance shows speciesspecific features in fungi, diagnosis at the species level is of great importance. In addition to the presence of resistance at the species level, isolate-specific resistance development can also be observed, so species-level identification studies with yeasts are as important as the prevention of fungal biofilms (Al-Hatmi et al., 2016).

Another important point in fungi is rapid spread. $C$. auris Satoh \& Makimura is a new yeast strain that causes invasive infections and is resistant to the existing antifungals. C. auris causes serious outbreaks in patients hospitalized in many countries and progresses with high mortality. Its rapid spread is another matter as important as its resistance to antifungals (Baillie and Douglas, 2000). Therefore, it is very important to correctly identify the organism and to treat it properly with the new antifungal approaches to control this pathogen. Because the problems originating from this fungal pathogen cannot be overcome with the existing methods.

Biofilm studies have been continuing with an increasing speed especially in the last three years. While the microorganism alone is not completely defeated in the face of man, the new target is in a different appearance and a stronger community. Combating infections caused by biofilm appears to be very difficult, as it is directly related to tissue damage during application. Reliable sampling and measurement techniques must be developed to control biofilm formation.

As a result, after the literature review; we think that increasing the number of studies on biofilm is important, especially in vivo studies should become widespread, analysis of genes and gene products associated with biofilms, i.e. proteomics studies, should continue increasing, and that a "problem-target-solution" approach should be adopted in overcoming the problems caused by fungal biofilms by researching new molecules that prevent biofilm formation.

\section{References}

Akan E, Kınık Ö (2014). Biyofilm oluşum mekanizması ve biyofilmlerin gıda güvenliğine etkisi. Gıda ve Yem Bilimi Teknolojisi Dergisi 14: 42-51. 
Al-Hatmi AM, Normand AC, Ranque S, Piarroux R, Meletiadis JF, Meis J (2016). Comparative evaluation of Etest, EUCAST, and CLSI methods for amphotericin B, voriconazole, and posaconazole against clinically relevant Fusarium species. Antimicrobial Agents Chemotherapy 61(1): 1671-1677.

Albuquerque P, Casadevall A (2012). Quorum sensing in fungi - a review. Medical Mycology 50(1): 337-345.

Andersen KS, Bojsen R, Sorensen LGR, Nielsen M, Lisby M, Folkesson A, Regenberg B (2014). Genetic basis for Saccharomyces cerevisiae biofilm in liquid medium. Genetics 4(9): 1671-1680.

Allison DG, Lappin-Scott HM, Wilson M (2000). Bacterial biofilms in human gastrointestinal community structure and cooperation in biofilms. Cambridge: Cambridge University Press.

Baillie GS, Douglas LJ (2000). Matrix polymers of Candida biofilms and their possible role in biofilm resistance to antifungal agents. Journal of Antimicrobial Chemotherapy 46: 397-403.

Brooks JD, Flint SH (2008). Biofilms in the food industry: Problems and potential Solutions. International Journal of Food Science Technology 43: 2163-2176.

Chandra J, Kuhn DM, Mukherjee PK, Hoyer LL, McCormick T, Ghannoum MA (2001). Biofilm formation by the fungal pathogen Candida albicans: Development, architecture, and drug resistance. Journal of Bacteriology 183: 5385-5394.

Chen H, Fujita Q, Feng JC, Fink GR (2004). Tyrosol is a quorum sensing molecule in Candida albicans, Proceedings Naturaes. Academia Sciense 101: 5048-5052.

Costerton JW, Stewart PS, Greenberg EP (1999). Bacterial biofilms: a common cause of persistent infections. Science 284(5418): 1318-1322.

D’Acunto B, frunzo L, Klapper I, Mattei M (2015). Modeling multispecies biofilms including new bacterial species invasion. Mathematical Biosciences 259: 20-26.

Dimakopoulou-Papazoglou, D, Lianou A, Koutsoumanis KP (2016). Modelling biofilm formation of Salmonella enterica ser. Newport as a function of $\mathrm{pH}$ and water activity. Food Microbiology 53: 76-81.

Douglas LJ (2002). Medical importance of biofilms in Candida infections. Revista Iberoamericana Micologia 19: 139-143.

Fanning S, Mitchell AP (2012). Fungal biofilms. PLOS Pathogens 8(4): 17-24.

Fleming D, Rumbaugh KP (2017). Approaches to dispersing medical biofilms. Microorganisms 5(2): 15-22.

Foreman A, Psaltis AJ, Tan LW, Wormald PJ (2009). Characterization of bacterial and fungal biofilms in chronic Rhinosinusitis. American Journal of Rhinology and Allergy 23(6): 1120-1126.

Güvense NC, Ekmekcioğlu S (2016). Biyofilm kontrolünde biyositler ve etki tarzları. Mikrobiyoloji Dergisi 14: 1-19.

Hornby JM, Jacobitz-Kizzier SM, McNeel DJ, Jensen EC, Treves DS, Nickerson KW (2004). Inoculum size effect in dimorphic fungi: extracellular control of yeast-mycelium dimorphism in Ceratocystis ulmi. Applied and Environmental Microbiology 70: 1356-1359.

Kumamoto CA (2011). Inflammation and gastrointestinal Candida colonization. Current Opinion in Microbiology 14(4): 386391.

Laffey SF, Butler G (2005). Phenotype switching affects biofilm formation by Candida parapsilosis. Microbiology 151: 10731081.

Pascual A (2002). Pathogenesis of catheter-related infections: Lessons for new designs. Clinical Microbiology Infectious 8: 256264.

Pittet D, Li N, Woolson RF, Wenzel RP (1997). Microbiological factors influencing the outcome of nosocomial bloodstream infections: A 6-year validated, population-based model. Clinical Infectious Diseases 24: 1068-1078.

Ramage G, Jose A, Coco B, Rajendran R, Rautemaa R, Murray C, Lappin D, Bagg J (2011).Commercial mouthwashes are more effective than azole antifungals against Candida albicans biofilms in vitro. Oral Surgery Oral Medicine Oral Pathology Oral Radiology Endoddontics 111(4): 456-460.

Semighini CP, Hornby JM, Dumitru R, Nickerson KW, Haris SD (2006). Farnesol induced apoptosis in Aspergillus nidulans reveals a possible mechanism for antagonistic interactions between fungi. Moleculer Microbiology 59: 753-764.

Shchepin R, Dumitru R, Nickerson KW, Lund M, Dussault PH (2005). Biologically active fluorescent farnesol analogs. Chemistry Biological 12: 639-641.

Shchepin R, Hornby JM, Burger E, Niessen T, Dussault P, Nickerson KW (2003). Quorum sensing in Candida albicans: Probing farnesol's mode of action with 40 natural and synthetic farnesol analogs. Chemistry Biological 10: 743-750.

Simões M, Simões LC, Vieira MJ (2010). A review of current and emergent biofilm control strategies. Food Science and Technology 43: 573-83.

Szafrański SP, Winkel A., Stiesch M (2017). The use of bacteriophages to biocontrol oral biofilms. Journal of Biotechnology 250: 29-44.

Van Houdt R, Michiels CW (2010). Biofilm formation and the food industry, a focus on the bacterial outer surface. Journal of Applied Microbiology 109: 1117-31.

Westwater C, Balish E, Schofield DA (2005). Candida albicans-conditioned medium protects yeast cells from oxidative stress: A possible link between quorum sensing and oxidative stress resistance. Eukaryot Cell 4: 1654-1661. 